\title{
Study of Major Issues and Their Impact on DVR System Performance
}

\author{
Sunil Kumar Gupta, H.P. Tiwari, Ramesh Pachar
}

\begin{abstract}
This paper explains the issues and the impact of various factors on performance of Dynamic Voltage Restorer (DVR) system. A DVR is connected in power system for series voltage compensation. Voltage sags have significant affect on the performance of sensitive loads present in the distribution system. The impact of voltage, energy, power, DVR rating, maximum load, power factor, maximum depth and duration of voltage sag, efficiency \& losses, harmonics, frequency and transformer on proper functioning of DVR system is studied.
\end{abstract}

Index Terms-Compensation, Dynamic Voltage Restorer, Voltage Sag, Power Quality

\section{INTRODUCTION}

Power quality means maintaining nearly sinusoidal voltage at frequency $50 / 60 \mathrm{~Hz}$. Voltage sag is broadly considered as a short duration voltage variation and method of characterization involves both magnitude and duration. The duration of voltage sag varies between five cycles to a minute. To prevent sensitive load from sag interruption in the source side, a series connected custom power device is used. SSSC (static synchronous series compensator) and DVR both are presently used for series voltage sag compensation. Operating principle and functioning of these devices differ significantly as the SSSC injects a balance voltage in series whereas the DVR compensates the unbalance in supply voltage of different phases. The DVR supplies the active power with help of DC energy storage and required reactive power is generated internally without any means dc storage. DVR can compensate voltage at both transmission and distribution sides. Usually a DVR is installed on a critical load feeder. During the normal operating condition (without sag condition) DVR operates in a low loss standby mode [1]. During this condition the DVR is said to be in steady state. When a disturbance occurs (abnormal condition) and supply voltage deviates from nominal value, DVR supplies voltage for compensation of sag and is said to be in transient state.

The DVR is connected in series between the load and the supply voltage [2]. It basically supplies the voltage difference (difference between the pre sag and sag voltage) to transmission line and maintains the pre sag values condition in the load sides [3]. Use of DVR is proposed in low and medium voltage distribution network to protect sensitive load from sudden voltage dips/sag [4]. Pulse width modulated inverter is used to vary the amplitude and the phase angle of the injected voltages, thus allowing the control of both real and reactive power exchange between the distribution system and the load [5]. For proper voltage sag compensation it is necessary to derive suitable and fast control scheme for inverter switching. The general requirement of a control scheme is to obtain an ac waveform with minimum total harmonic distortion (THD) and best dynamic response against supply and load disturbance when the DVR is operated for voltage sag compensation [6].

This paper is organized into XV sections. Section I discusses introduction. Next impact of different factors on performance of DVR is presented in various sections through $\mathrm{V}$ to $\mathrm{XV}$.

DVR structure is representing in section II. Control Philosophy is presented in section III. Parameter of DVR Test System is represented in section IV. Section V presents the voltage issue. DC Energy storage issue is presented in section VI. Power issue is presented in section VII. Section VIII explains the DVR rating issue. Maximum load and power factor issue is discussed in section IX. Maximum depth and duration of voltage dip is presented in section $\mathrm{X}$. Efficiency and losses of DVR are presented in section XI. Frequency issue is represents in section XII. Section XIII discusses the Harmonics issue. Transformer rating issues are presented in section XIV and conclusions are given in section $\mathrm{XV}$.

\section{DVR STRUCTURE}

Fig. 1 shows the basic structure of dynamic voltage restorer. It consists of DC energy storage unit, a capacitor, VSI converter, low pass filter and a voltage injection transformer. The function of each component of DVR is as follows.

Sunil Kumar Gupta is research scholar in Department of Electrical Engineering with the Malaviya National Institute of Technology, Jaipur, Rajasthan, INDIA (e-mail: Sunil_sunel@yahoo.co.in).

Dr. H. P. Tiwari is Reader in Department of Electrical Engineering with the Malaviya National Institute of Technology, Jaipur, Rajasthan, INDIA (e-mail: harpaltiwari@yahoo.co.in).

Ramesh Pachar is research scholar in Department of Electrical Engineering with the Malaviya National Institute of Technology, Jaipur, Rajasthan, INDIA (e-mail: rameshpachar@rediff.com). 


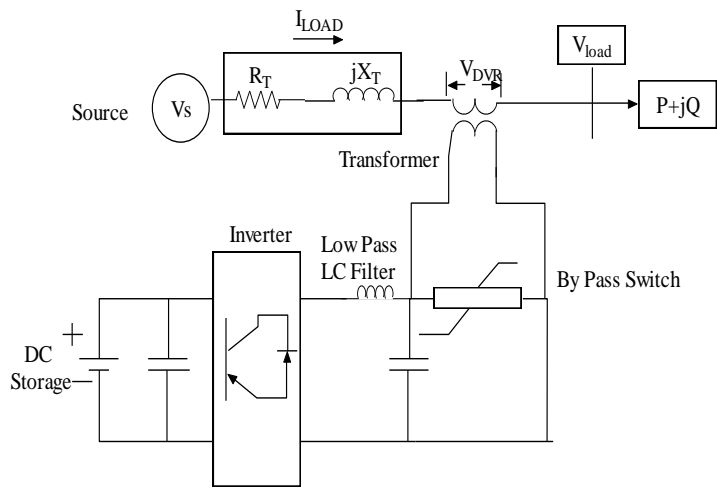

Fig.1 Basic Structure of Dynamic Voltage Restorer

(a) Energy Storage Unit: It is responsible for energy storage in DC form, Flywheels, Lead acid batteries, Superconducting magnetic energy storage (SMES) and Super-Capacitors can be used as energy storage devices. It is supplies the real power requirements of the of the system when DVR is used for compensation [3].

(b) Capacitor: DVR has a large DC capacitor to ensure constant input supply to inverter.

(c) Inverter: An Inverter system is used to convert from dc storage to ac [7].rating of the VSI converter is of low voltage and high current type due to step up injection transformer in the DVR compensation technique [3].

(d) Passive Filters: Filters are used to convert the PWM inverted pulse waveform into a sinusoidal waveform. This is achieved by removing the unnecessary higher order harmonic components generated during the $\mathrm{DC}$ to $\mathrm{AC}$ conversion in the Voltage Source Inverter (VSI), higher orders harmonic components distort the compensated output voltage [8].

(e) By-Pass Switch: it is used to protect the inverter from high currents. When the event of a fault or a short circuit on downstream, the DVR changes into the bypass condition where the VSI inverter is protected against over current flowing through the power semiconductor switches. The rating of the DVR inverters become limiting factor for normal load current seen in the primary winding and reflected in the secondary winding of the series insertion transformer. For line currents exceeding the rating, a bypass scheme is incorporated to protect the power electronics devices [9]

(f) Voltage Injection Transformers: In a three-phase system, three Single-phase transformer units or one three phase transformer unit can be used for voltage injection purpose. [8].

\section{CONTROL PHILOSOPHY}

Voltage sag is created at load terminals via a three-phase fault as shown in Fig.3. Load voltage is sensed and passed through a sequence analyzer. The magnitude component is compared with reference voltage $\left(\mathrm{V}_{\text {ref }}\right)$. Pulse width modulated (PWM) control technique [11] is applied for inverter switching so as to produce a three phase $50 \mathrm{~Hz}$ sinusoidal voltage at the load terminals. Chopping frequency is in the range of few $\mathrm{KHz}$. The IGBT inverter is controlled with PI controller in order to maintain 1 per unit voltage at the load terminals.

PI Controller (proportional-integral controller) [3] [11] is a close loop controller which drives the plant to be controlled with a weighted sum of the error (difference between the output and desired set-point) and the integral of that value. An advantage of a proportional plus integral controller is that the integral term in a PI controller causes the steady-state error to be zero for a step input. PI controller input is an actuating signal which is the difference between the $V_{\text {ref }}$ and $\mathrm{V}_{\text {in. }}$ Output of the controller block is of the form of $\delta$

Output of comparator $=\mathrm{V}_{\text {ref }}-\mathrm{V}_{\text {in }}$.

Where (1p.u. =Base Voltage)

$\mathrm{V}_{\text {ref }}$ equal to 1 p.u. voltage

$\mathrm{V}_{\text {in }} \quad$ voltage in p.u. at the load terminals. The angle $\delta$ is provided to the PWM signal generator to obtain desired firing sequence.

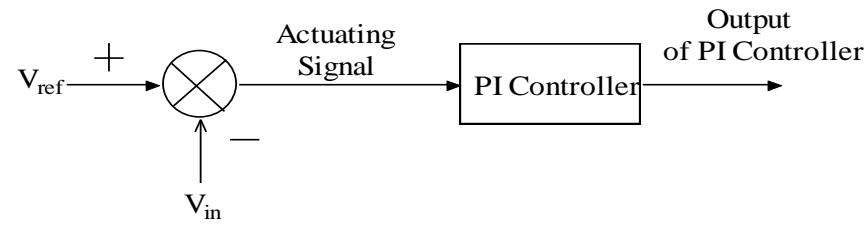

Fig.2 Indirect PI Controller

The sinusoidal signal $\mathrm{V}_{\text {control }}$ is phase-modulated by means of the angle $\delta$.

$$
\text { i.e., } \begin{aligned}
\mathrm{V}_{\mathrm{B}} & =\operatorname{Sin}(\omega \mathrm{t}+\delta) \\
\mathrm{V}_{\mathrm{Y}} & =\operatorname{Sin}(\omega \mathrm{t}+\delta+2 \pi / 3) \\
\mathrm{V}_{\mathrm{B}} & =\operatorname{Sin}(\omega \mathrm{t}+\delta+4 \pi / 3)
\end{aligned}
$$

\section{Parameters Of Dvr Test System}

Electrical circuit model of DVR Test System is shown in Fig.3. System parameters are listed in Table 1. Voltage sag is created at load terminals via a three-phase fault as shown in Fig.3. Load voltage is sensed and passed through a sequence analyzer. The magnitude component is compared with

\begin{tabular}{|c|c|c|}
\hline S.No. & $\begin{array}{c}\text { System } \\
\text { Quantities }\end{array}$ & Standards \\
\hline 1 & Capacitance & $750 \mu \mathrm{s}$ \\
\hline 2 & Inverter & $\begin{array}{l}\text { IGBT based, } 3 \text { arms }, \\
6 \text { pulse, } \\
\text { Carrier frequency }=1080 \\
\mathrm{~Hz}, \text { Sample time }=5 \mu \mathrm{s}\end{array}$ \\
\hline 3 & Fault Resistance & $0.66 \mathrm{ohms}$ \\
\hline 4 & Load & $30 \mathrm{KW}, 100 \mathrm{VAR}$ \\
\hline 5 & $\begin{array}{l}\text { Transmission } \\
\text { Line Parameter }\end{array}$ & $\mathrm{R}=0.001 \mathrm{ohms}, \mathrm{L}=0.005 \mathrm{H}$ \\
\hline 6 & PI Controller & $\begin{array}{l}\mathrm{K}_{\mathrm{P}}=0.5 \\
\mathrm{~K}_{\mathrm{i}}=50 \\
\text { Sample time }=50 \mu \mathrm{s}\end{array}$ \\
\hline
\end{tabular}
reference voltage $\left(\mathrm{V}_{\text {ref }}\right)$.

TABLE.1 System Parameters 
MATLAB Simulation diagram of the test system is shown in Fig.4. System comprises of $13 \mathrm{kV}, 50 \mathrm{~Hz}$ generator, Feeding transmission lines through a 3-winding transformer connected in $\mathrm{Y} / \Delta / \Delta, 13 / 115 /(11 / 16 / 25 / 40 / 60) \mathrm{Kv}$.

\section{Voltage Issue}

Voltage sag is generally caused by the faults. It may be occur in system due to unbalance voltage and current, in excess of voltage, reversal of power, under frequency, temperature rise, power swing and instability. The fault which may have any of the following charge: reduction in the line voltage, overheating, disturbance to the stability of the electrical system, significant reduction in the voltage on the healthy feeder connected to the system having fault. It may cause the excessive large current which is dangerous the motors or other connected equipment.

When the fault condition is applied in the above MATLAB simulation system from $0.4 \mathrm{sec}$ to $0.6 \mathrm{sec}$ with help of fault resistance 0.66 , voltage sag is appeared in system and it draw large current at the time of sag duration. Simulation result shows that in Fig.5 and Fig.6 w.r.t voltage sag duration and fault current.

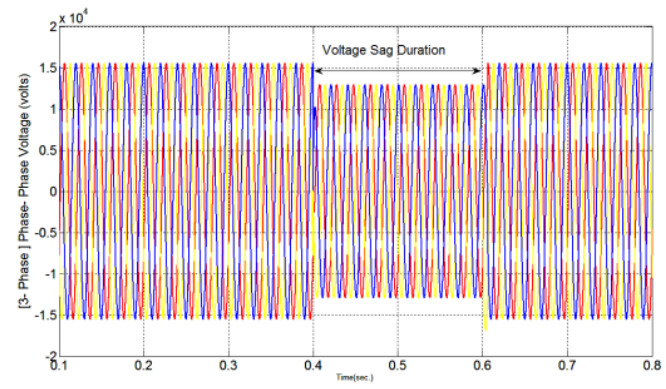

Fig.5 Three phase: Phase to Phase Voltage

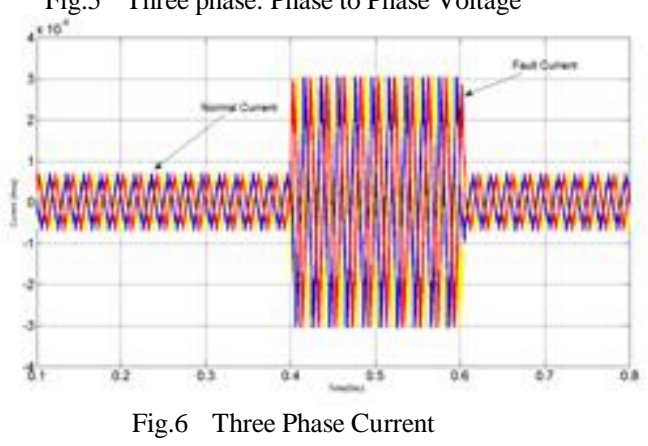

A DVR has the capability to inject voltage up to a define threshold [12]. For voltage sag mitigation; Voltage is fed in the suitable required quantity, for voltage sag compensation via the DVR compensation technique. When reducing the operating cost it is necessary requirement that voltage compensation is applied in proper required quantity. Reduction in voltage drop in normal operating condition means without sag condition it is also effect the operating cost factor.

\section{DC ENERGy Storage IsSUE}

The amount of energy which has to be stored in the capacitor bank depends on the installed load MVA and the power factor [1].

A DVR design that includes a large energy reserve implies a high price tag. So it is normally sized as possible for affordability. Energy is used maintain load voltage. Some sag can drain the storage rapidly. And the control strategy can decrease the threat of load tripping caused by inadequate energy storage [12].

DC energy storage is used is as an inverter input supply. Inverter which is supply the voltage in sag (voltage) condition to maintain a proper pre decided voltage level at the load terminal. The size of energy storage device should be low as possible in order to reduce the operating and fixed cost.

Experience shows that minimum DC battery storage capacities (in DVR compensation technique) for maintaining various transmission voltages at load terminals are given in Table 2 .

TABLE. 2

\begin{tabular}{|c|c|c|}
\hline $\begin{array}{c}\text { Voltage at } \\
\text { load } \\
\text { terminal } \\
\left(\mathbf{V}_{\text {Load }}\right)\end{array}$ & $\begin{array}{c}\text { Required DC } \\
\text { Storage voltage } \\
\left(\mathbf{V}_{\mathbf{D C s}}\right)\end{array}$ & $\begin{array}{c}\text { Required DC } \\
\text { Storage voltage } \\
\left(\% \text { age of } \mathbf{V}_{\text {Load }}\right)\end{array}$ \\
\hline $11 \mathrm{kV}$ & $5 \mathrm{kV}$ & 45.45 \\
\hline $16 \mathrm{kV}$ & $8.5 \mathrm{kV}$ & 53.12 \\
\hline $25 \mathrm{kV}$ & $16 \mathrm{kV}$ & 64 \\
\hline $40 \mathrm{kV}$ & $30 \mathrm{kV}$ & 75 \\
\hline $60 \mathrm{kV}$ & $48 \mathrm{kV}$ & 80 \\
\hline
\end{tabular}

For a load terminal, Voltage sag compensation, require a DC Energy Storage voltage which is supplied to as an input inverter, can be estimated for from equation 5, 6 and 7 as shown below.

$$
\begin{aligned}
& \mathrm{V}_{\text {DCs }}=-5.55+0.89 \mathrm{~V}_{\text {Load }} \\
& \mathrm{V}_{\text {DCs }}=-4.2+0.79 \mathrm{~V}_{\text {Load }}+0.0014 \mathrm{~V}_{\text {Load }}^{2} \\
& \mathrm{~V}_{\text {DCs }}=-0.83+0.38 \mathrm{~V}_{\text {Load }}+0.015 \mathrm{~V}_{\text {Load }}^{2}+0.00013 \mathrm{~V}_{\text {Load }}^{3}
\end{aligned}
$$

Where

$$
\begin{aligned}
& \mathrm{V}_{\text {Load }} \text { is Voltage at load terminal. } \\
& \mathrm{V}_{\mathrm{DCs}} \text { is DC Storage voltage required for sag } \\
& \text { compensation. }
\end{aligned}
$$

\section{DVR POWER ISSUE}

While the DC link stores the power, the majority of power is often converted from the supply or from a large DC storage via a converter that regulates the $\mathrm{DC}$-link voltage. The rating of this converter imposes a power limit [12].

The selection of suitable power limit and their quantity play an important role in the working of a DVR compensation technique. The rating of the inverter introduces the power limit in the DVR system. During transient condition the DVR supply or absorb the real power whereas in steady state condition it neither supplies nor absorb real power. In the steady state condition, the DC storage only supplies real power for losses in the inverter. The power rating of any compensation device depends upon the application to which is to be used [14]. 


\section{DVR DESIGN CRITERIA AND RATING ISSUE}

The rating of a DVR and the choice of optimal technology depends on the distribution of remaining voltage, fixed cost and running cost of a DVR depends on voltage rise capability. The random failure location in network are calculated by analysis of long time period data and an appropriate rating is selected by means of probability based analysis methods namely Monte-Carlo method and Quasi-Deterministic method [15]. CBEMA curve may be plotted by analysis of the fault location and impedance during the fault. Long Term data is recorded for depth of voltage sag and its duration and analysis is carried out on basis of probability of the fault. Recorded majority of the faults area, indicate the sensitivity area of the system. The protection is required in this area for voltage sag reduction [21].

Performance and DVR rating depends upon total maximum MVA-load, power factor, maximum voltage dips to be compensated, during steady state condition maximum allowed voltage drop, short circuit impedance of the booster transformer. Short circuit impedance and connection of step down transformer at input and output sides of DVR with short circuit power [1]. DVR designing issue may consider sensitivity of the protected load (amount of sensitivity means MVA rating) and duration and depth.

\section{MAXIMUM LOAD AND POWER FACTOR}

The total load size connected at load terminal affects the size and amount of energy storage device, rating of capacitor, current rating of voltage source inverter (VSI), rating and size of voltage injection transformer for suitable voltage sag compensation [16]. Load poor power factor increase the losses and excessive heat reduces the life span of feeder.

\section{MaXimum Depth And Duration Of Voltage Dip}

Voltage dip is generated by faults. Fault depth and duration determine its effect the voltage dip. The level of voltage dip is determined by the calculation of fault impedance, source impedance and line impedance. Voltage dips also effect the maximum rating of the VSI and voltage injection transformer [16]. By using circuit breaker and fuse to provide protection, the $I^{2} R$ characteristic gives the information about the voltage dip. As fault current value approaches higher value the operating time for the fuse falls and it is calculated by using time-current characteristics [15].

\section{EFFICIENCY AND LOSSES}

The efficiency of the DVR is calculated by the load to be protected [17] and by calculating losses considering the operation during standby condition and all auxiliary equipments which are in operation with inverter losses, transformer losses and dc link losses. Direct connection of VSI to the primary winding of injected transformer results in losses in the transformer. Iron losses increase due to high frequency flux variation. To reduce these losses a low pass filter is placed in between the VSI and injected transformer. Typically an efficiency of $>98 \%$ can be achieved.

\section{FREQUENCY ISSUE}

Experience indicate that Lighting, motors, transformers, generators and transmission lines all have characteristics which depend on the power frequency. In an interconnected power system, the rated generation frequency of all the accessories or equipments which are connected through the interconnected system must be same. If it is not so than injection transformers core losses increases due to mismatching of frequency.

\section{HARMONICS ISSUE}

As VSI is a Power electronics device, it is a fast switching device and adds harmonics in the system voltage and increase the total harmonics distortion of the system.

Simulation result shows that when system simulation is carried on without DVR with voltage sag $19 \%$ as shown Fig.7(a) Then THD is $0.00 \%$ as shown Fig.7(b).
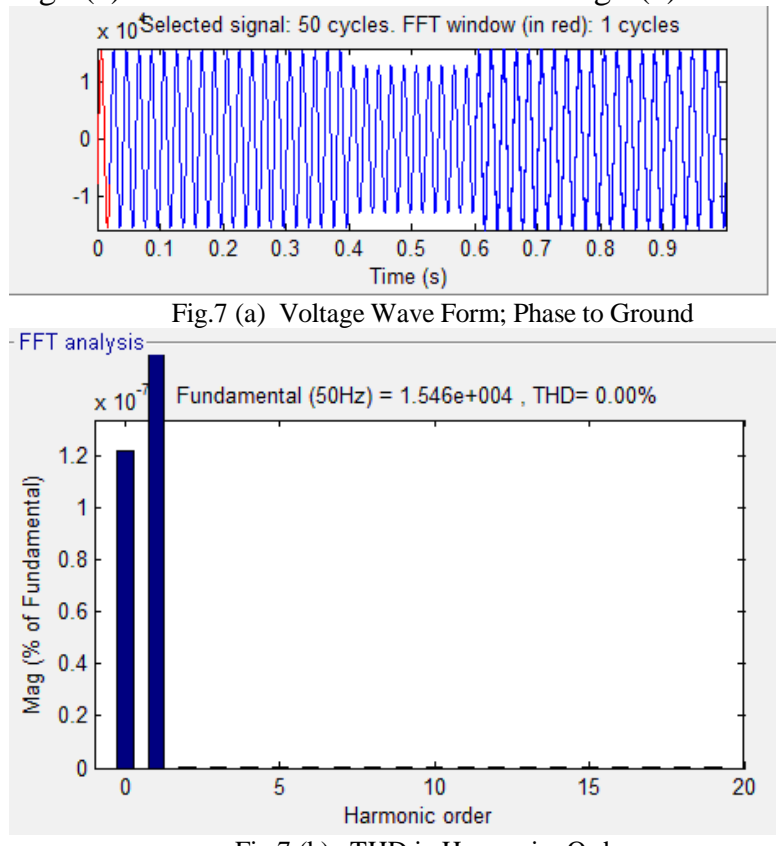

Fig.7 (b) THD in Harmonics Order

When DVR with energy storage capacity $5 \mathrm{kv}$, MATLAB simulation is carried out with PI controller voltage sag $0.00 \%$ as shown Fig.8. (a) Then total harmonic distortion is calculated $21.41 \%$ as shown Fig.8. (b).

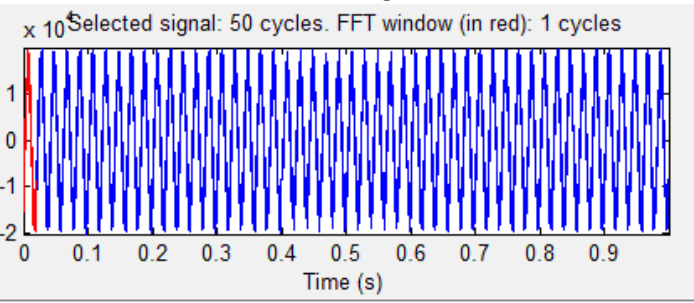

Fig.8(a) Voltage Wave Form; Phase to Ground 


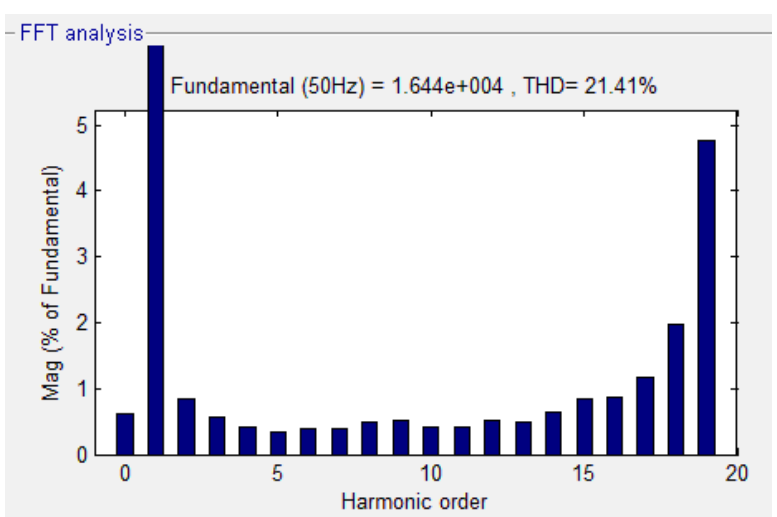

Fig.8(b) THD in Harmonics Order

Harmonic component in the system can create system saturation problem and it causes needless losses. It may result in heating of the transformer coil and core due to excessive magnetizing current and core losses. THD also has an effect on the voltage sag compensation by the DVR injection transformer. To bring THD within permissible limits a low pass filter is essential.

A damped low pass filter is sufficient to bring down the harmonics within permissible limits. This can either be placed on the low voltage side of the series transformer or on high voltage side, if placed in high voltage side; the filter can make use of the transformer leakage reactance as part of the low pass filter. If placed on the low voltage side the filter is not connected to the network if the low voltage side of the DVR is disconnected [8].

\section{TRANSFORMER ISSUE}

For proper voltage sag compensation by the operation of the DVR, rating and design issue of series injection transformer are of much apprehension. Different transformer issues considered for compensation technique is over rating, current rating, temperature rating, surge voltage, short circuit impedance, voltage underrating of the transformer and available transport facilities. In addition to this cost, performance, saturation and the sizing issues are also important while selecting a transformer for a DVR system. [18].

\section{CONCLUSION}

This paper presents various issues relevant to the design and evaluation of DVR for voltage sag compensation. The major factors and their impact on DVR performance are presented in a way which is useful in selection of a DVR system for a specific application.

\section{REFERENCES}

[1] Toni Wunderline and Peter Dhler, "Power Supply Quality Improvement with A Dynamic Voltage Restorer (DVR) IEEE, 1998.

[2] Carl N.M.Ho, Henery and S.H. Chaung, "Fast Dynamic Control Scheme for Capacitor- Supported Dynamic Voltage Restorer: Design Issues, Implementation and Analysis. IEEE, 2007.
[3] Kasuni Perera, Daniel Salomon son and Arulampaiam, Atputharajah, Sanath Alahakoon, "Automated Control Technique for A Single Phase Dynamic Voltage Restorer” IEEE, 2006.

[4] Yun Wei Li.Poh Chiang Loh, Frede Blaabje and D.Mahinda Vilathgamuwa, "Investigation and Improvement of Transient Response of DVR at Medium Voltage Level. IEEE, 2006.

[5] V.K.Ramachandramurthy,C.Fitzer,A.Arulampalm.,C.Zhan, M. Barnes and N. Jenkins 'Control of Battery Supported Voltage Restorer, IEE, September 2002, Vol. 149 No.5,

[6] D.Mahinda, Vilathgamuwa, H.M.Wijekoon and S.S.Choi, “ Interline Dynamic Voltage Restorer: A Novel and Economical Approach For Multi-Line Power Quality Compensation” IEEE 2003.

[7] R.Akkaya, A. A. Kulaksiz, "A Microcontroller-Based Stand-Alone Photovoltaic Power System for Residential Appliances” Applied Energy 78, 2004, 419-431.

[8] C.Zhan, M. Barnes, V.K. Ramachandaramurthy, N. Jenkis, "Dynamic Voltage Restorer with Battery Energy Storage for Voltage Dip Mitigation" Power Electronics and Variable Speed Drives, 18-19, Conference Publication No. 475, IEE September 2000.

[9] Changjian Zhan, V.K. Ramachandraramurthy, A.Arulampalam, M.Barnes and G.Strbac N.Jekin, "Dynamic Voltage Restorer Based on Voltage Space Vector PWM Control", IEEE 2001.

[10] John Godsk, Nielsen and Freed Blaabjerg, "Control Strategies for the Dynamic Voltage Restorer Compensation Voltage Sag With Phase Jump. IEEE.2001.

[11] S.V Ravi Kumar, S. Siva Nagaraju, "Simulation of D-STATCOM and DVR in Power Systems" ARPN Journal of Engineering and Applied Sciences Vol. 2, No. 3, June 2007.

[12] Brice J .Quirel, BrianK Johnson and Herb L.Hess "Mitigation of voltage sags with Phase jump using a Dynamic Voltage Restorer" IEEE 2006.

[13] Christoph Mayer, Christoph Romaus and Rik W.De Doncker "Optimized Control Strategy for A Medium-Voltage DVR” IEEE 2005.

[14] C.P.Fizer, Y.S.Lim, C.Zhan, V.K.Ramachandraramurthy, A.Arulampalam,M.Barnes and G.Strbac N.Jekin, "Mitigation Of Voltage Sags Embracing A Prediction Technique And The Use of A Dynamic Voltage Restorer" Cired 2001,18-21 June 2001, Conference Publication No.482, IEEE 2001.

[15] Herwing Renner and Manfred Sakulin, "Calculation of voltage dips in meshed grids,", 11 th International Conference on Harmonics and Quality of Power, 2004, vol., no., pp. 666-671, 12-15 Sept. IEEE.

[16] Hilmay Award, Jan Svensson and Math H.J. Bollen, "Static Series Compensator for Voltage Dip Mitigation”, IEEE 2003.

[17] P.Daehler and R.Affolter "Requirement and Solution for Dynamic Voltage Restorer, A Case Study", IEEE, 2000.

[18] Sasitharan S., Mahesh K. Mishra, B. Kalyan Kumar and Jayashankar, "Rating And Design Issues of DVR Injection Transformer " IEEE 2008.

[19] N. Hamzah, M.R. Muhamad and P.M.Arsad, "Investigation on the Effectiveness of Dynamic Voltage Restorer for Voltage Sag Mitigation" IEEE 2007.

[20] Arindam Ghosh and Generd Ledwich "Power Quality Enhancement Using Custom Power Devices" Kluwer Acadmic Publisher, (Boston, Dordrehnt, London), 2002.

[21] R. S. Thallam and G. T. Heydt, "Power Acceptability and Voltage Sag Indices in the Three Phase Sense" presentation at the Panel Session on "Power Quality - Voltage Sag Indices" IEEE PES Summer Meeting, July 2000 , Seattle, WA.

H.P. Tiwari received the B.E. degree in electrical engineering in year 1982 and M.sc. Engineering degree in electrical engineering in year 1986. and the PhD degree awarded from University of Rajasthan in year 2000. He is working as a Reader in Department of Electrical Engineering of Malaviya National Institute of Technology (MNIT), Jaipur (INDIA. His research interests include power electronics, electrical machines and drive and non- conventional energy sources.

Sunil Kumar Gupta received B.E. (Electrical Engg.) from the University of Rajasthan, M.E. in Power Electronics Machine Design and Drives India in 2006. . He is a research scholar in Department of Electrical Engineering of Malaviya National Institute of Technology (MNIT), Jaipur (INDIA). His field of interest includes power electronics, electrical machines and control system.

Ramesh kumar Pachar received B.E. (Electrical Engg) in 1996, M.Tech in Power system in year 2005. He is a research scholar in Department of Electrical Engineering of Malaviya National Institute of Technology (MNIT), Jaipur (INDIA). His field of interest includes, Power electronic applications in power system \& MATLAB applications to electrical engineering 


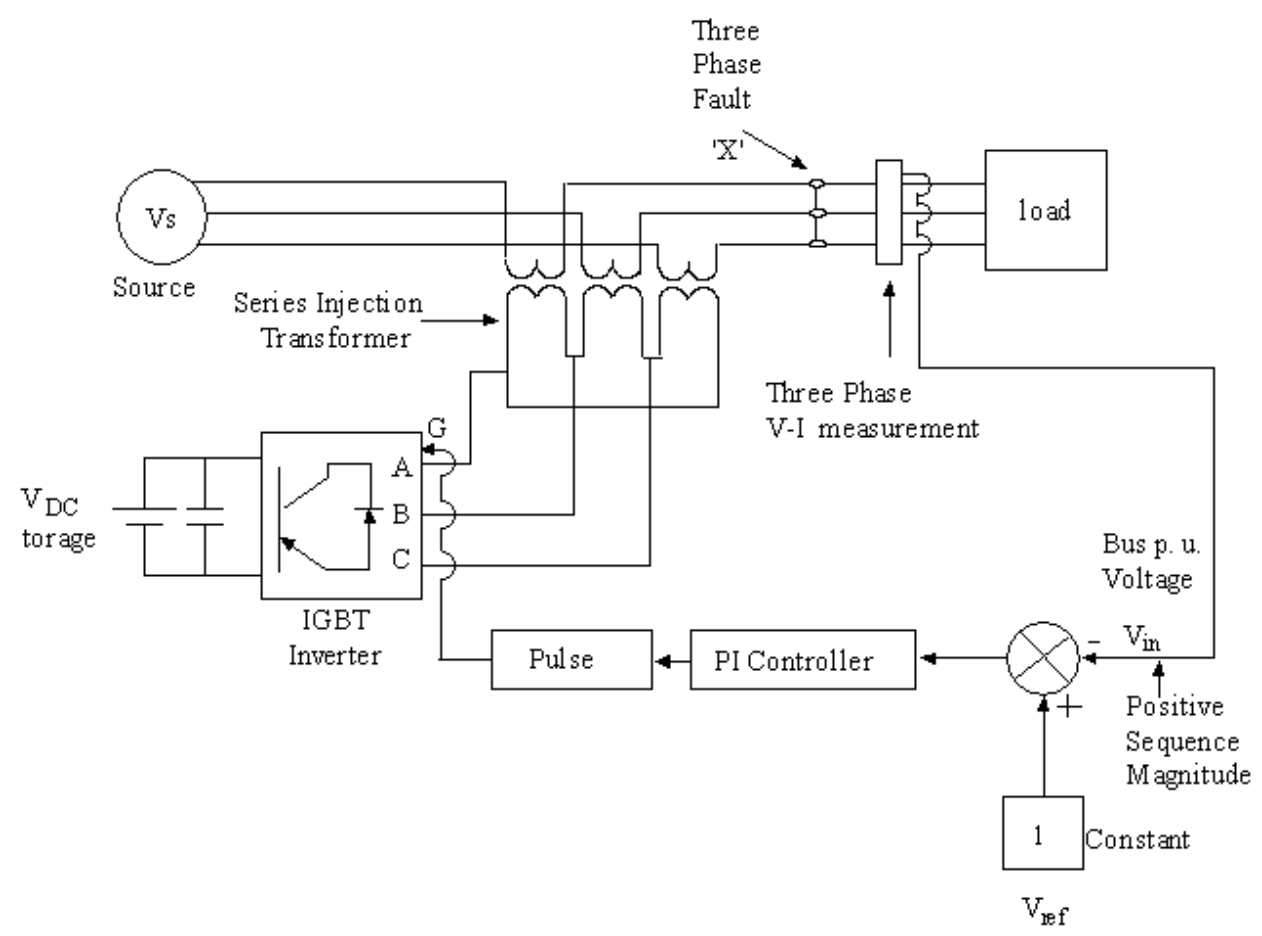

Fig.3 Circuit Model of DVR Test System

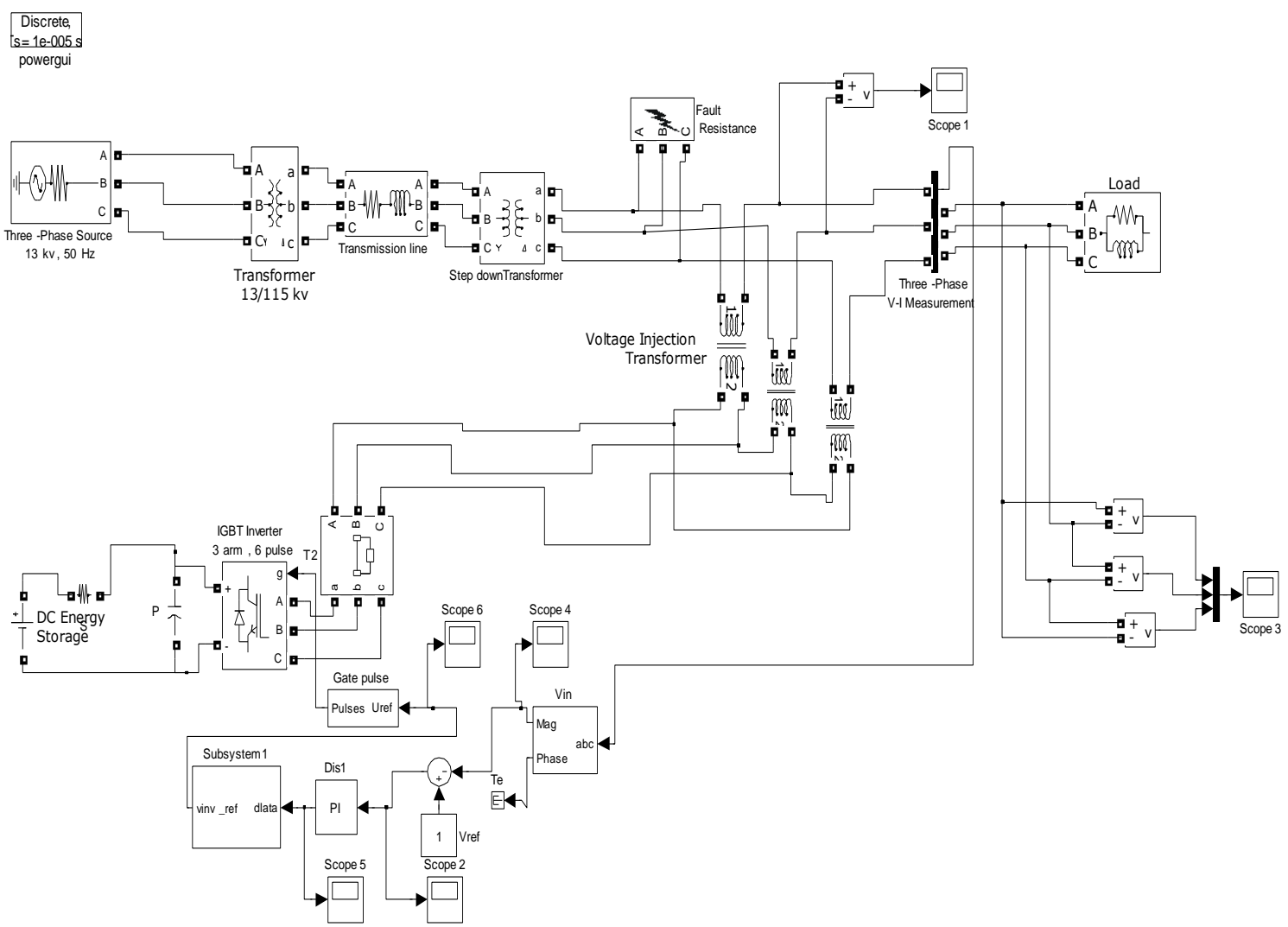

Fig.4 Simulation Model of DVR Test System 